\title{
SUSTAINABLE BEHAVIOUR IN HIGHER EDUCATION: ANTECEDENTS AND CONSEQUENCES
}

\author{
MERINDA HERRARI CHRISNUARTANTI PANDOWO*, BERNHARD TEWAL, VICTOR \\ PASKAH KALAWAT LENGKONG AND RUDY STEVEN WENAS
}

Faculty of Economics and Business, Sam Ratulangi University, Jl. Kampus Bahu, Manado 95115, Indonesia

*Corresponding author: merindapandowo@unsrat.ac.id

Submitted final draft: 15 November 2020 Accepted: 7 January $2021 \quad$ http://doi.org/10.46754/jssm.2021.10.007

\begin{abstract}
There is a need to integrate education into sustainable development in higher education. The practice of sustainability in higher education is to disseminate sustainable development knowledge. Furthermore, sustainable universities should not merely focus on greening their curriculum and management practices, but also ways to promote social and economic sustainability. This study aimed to test a model of the antecedents and consequences of sustainable behaviour in higher education. A total of 403 students participated in the survey and were selected using purposive sampling. The questionnaires were analysed using Partial Least Squares Path Modeling (PLS-PM) and XLSTAT2020 as the statistical analysis software. The findings revealed that personality influenced sustainable behaviour, attitude did not have a significant effect on sustainable behaviour, and sustainable behaviour had a significant relationship wtih happiness and life satisfaction. This research contributed to sustainability efforts through studies of sustainable behaviour, particularly the understanding on why students involved in sustainable behaviour. One of the findings did not support the hypothesis, yet it may still be useful and broadened the findings of the research. Further research is needed for the non-significant hypothesis.
\end{abstract}

Keywords: Sustainability, sustainable behaviour, individual difference, well-being.

\section{Introduction}

The concept of sustainability is often considered as an environmental concept, but it has a broader scope, which includes education as well. The consensus is that education is the means to attain sustainable development. Sustainability education or Education for Sustainable Development (ESD) is a learning approach that incorporates social, economic, and environmental dimensions as the pathway to sustainability.

Regarding sustainability, higher education has put significant efforts to address it in campus operations. Sustainable university refers to environmental, economic and social concerns that universities should have in their activities (Amaral et al., 2015). In fact, higher education takes a critical role in creating a sustainable future. Higher education may serve as a sustainable model and the practice of sustainability can be carried out through teaching and curriculum, research and scholarship, campus operations, management and community, and financial management (Alshuwaikhat et al., 2016).

University students, as the young generation, play a substantial role in addressing sustainability. The promotion of ESD in higher education is considered crucial to build a sustainable future and to place the younger generation at the centre of development (UNESCO, 2009). Strong student participation, engagement, and involvement can strengthen and contribute to sustainability efforts at the campus. Yet, Abubakar et al. (2016) found that student may show their awareness and concerns about campus sustainability, but they lack the interest and willingness to be involved in sustainability practice. Recycling, energy efficiency, water preservation, or the use of environmentally friendly devices and products are some of students' sustainability practices that promote sustainable behaviour.

Studying students' sustainable behaviour is important because it concentrates on behaviour 
that reduces negative environmental impact. Bechtel and Corral-Verdugo (2010) suggested the studying of the consequences of sustainable behaviour as human behaviour is determined by its antecedents and repercussions. Individual difference can be used to understand human behaviour. It is the personal attributes that vary one person to another (Griffin, 2013), including several factors, such as personality traits and attitudes (Mullins, 2016). Juárez-Nájera (2010) found that personality factors as the base of sustainable behaviour, and environmental attitude as a predictor of ecological behaviour (Kaiser et al., 1999). When people are aware of the positive consequences of practising sustainable behaviour, they are eager to participate. Previous studies indicated that participating in environmental behaviour contributes to a person's well-being. Life satisfaction is positively and significantly associated with diverse types of pro-environmental behaviour and people who engage in sustainable behaviour are found to feel happier than those who do not (Welsch \& Kühling, 2009; Choi, 2016).

The present study examined individual differences as the antecedents and human wellbeing as the consequences of having sustainable behaviour. It is designed to examine further the influence of personality and attitude on sustainable behaviour and sustainable behaviour on both happiness and life satisfaction.

\section{Sustainable Behaviour}

The relationship between human and the natural environment has long been the subject of research. Human behaviour has always been concerned with environmental problems (Vlek \& Steg, 2007). It leads to the emergence of sustainable behaviour (SB), an individual behaviour that aims to protect both the natural and the human/social environments (TapiaFonllem et al., 2013). In a similar definition, Bonnes \& Bonaiuto (2002) argued that SB requires people to engage in actions aimed at caring for others and to protect their biophysical environment. Previous studies have investigated factors that exert influence on sustainable behaviour, such as the socio-psychological model, time perspective, character strengths, incentives, and competition (Juárez-Nájera et al., 2010 ; Arnocky et al., 2014; Corral-Verdugo et al., 2015; Huber et al., 2017; Van Horen et al., 2018).

\section{Personality and Sustainable Behaviour}

Personality has long been studied to help predict certain behaviours. Personality is thought to influence behaviour through the types of traits and is reflected in behavioural patterns. Approaches to studying personality have developed with the trait approach, which is relatively stable, consistent, and endures internal characteristics. The Big Five personality traits are considered as the most basic dimensions of the structure of personality and consist of agreeableness, conscientiousness, openness to new experiences, extraversion and neuroticism. Agreeableness contrasts a prosocial and communal orientation towards others with antagonism; conscientiousness describes socially prescribed impulse control that facilitates task- and goal-directed behaviour, such as thinking before acting, delaying gratification, following norms and rules, and planning, organising, and prioritising tasks; openness to experience describes the breadth, depth, originality, and complexity of an individual's mental and experiential life; extraversion implies an energetic approach toward the social and material world; and, neuroticism contrasts emotional stability and even-temperedness with negative emotionality (John \& Srivastava, 1999). Previous studies have pointed out the importance of studying personality in predicting sustainable behaviour. Kvasova (2015) found that agreeableness, conscientiousness, extraversion, and neuroticism are positively associated with pro-environmental behaviour with no significant relationship between openness and ecological action. Poškus (2018) found that extraversion, openness, conscientiousness, and agreeableness are positively related to pro-environmental behaviour, while neuroticism is negatively related to pro-environmental behaviour. 
Hypothesis 1: Personality influences sustainable behaviour

\section{Attitude and Sustainable Behaviour}

Research on attitudes has been widely studied, especially in social science. Attitude is a strong determinant of behaviour (Polonsky et al., 2012). In the environmental domain, attitude is described as the cognitive and affective evaluation of the object environmental protection (Bamberg, 2003). Individual environmental concern is also known as environmental attitude (EA) and is considered a strong predictor of ecological behaviour (Kaiser et al., 1999). A positive attitude will make an individual support, understand, and carry out sustainable behaviour. In fact, positive attitudes towards the environment lead to proenvironmental behaviour (Bamberg \& Möser, 2007). Thus, sustainable behaviour is more likely to happen if a person has a positive attitude towards sustainability and believes that the behaviour is easy to perform. In contrast to Mainieri et al. (1997) and Ahmad et al. (2015), other studies found positive correlation between environmental attitudes and environmental behaviour behaviour (Kotchen \& Reiling, 2000; Mostafa, 2007).

Hypothesis 2: Attitude influences sustainable behaviour

\section{Sustainable Behaviour and Happiness}

The awareness of environmental protection has a major role in how the natural environment works in human happiness. In contrast to Ferrer-i-Carbonell and Gowdy (2007) and Di Tella and MacCulloch (2008), who found that environmental degradation has a negative impact on happiness, Tiwari and Mutascu (2015) reported no significant impact of environmental degradation and GDP on happiness. By practising sustainable behaviour, individuals can minimise the level of environmental degradation, thus, improve the level of happiness. Some studies have provided supportive evidence for a link between sustainable behaviour and happiness. Gardner and Prugh (2008) found that practising sustainable behaviour results in happiness and life satisfaction. Corral-Verdugo et al. (2011) and Choi (2016) found that sustainable behaviour significantly influences happiness.

Hypothesis 3: Sustainable behaviour influences happiness

\section{Sustainable Behaviour and Life Satisfaction}

Engaging with the natural environment is one path to contribute significantly to life satisfaction. Environmental problems reduce life satisfaction (Ferrer-i-Carbonell \& Gowdy, 2007). Furthermore, environmental concern is a prime mechanism for life satisfaction (Wang \& Kang, 2019). Man-made pollution, loss of biodiversity, and depletion of natural resources are some causes of environmental problems, especially their impacts on human well-being. Ferreira et al. (2013) found a negative impact of air pollution on life satisfaction. Thus, having sustainable behaviour would reduce the level of environmental degradation and improve life satisfaction. Previous findings examined the relationship between sustainable behaviour and life satisfaction. Brown and Kasser (2005) found that life satisfaction was related to smaller ecological footprints. Welsch and Kühling (2010) found a positive and significant association between life satisfaction and proenvironmental behaviour.

Hypothesis 4: Sustainable behaviour influences life satisfaction

\section{Materials and Methods}

A survey was carried out at the University of Indonesia (UI) and Bogor Agricultural Institute (IPB). These universities were chosen because they are ranked as the first and the second on the national level (Indonesian rankings) of UI GreenMetric World University Rankings in 2019. A total of 410 questionnaires were distributed and 403 questionnaires were completed, resulting in a $98.3 \%$ response rate. 
The sample size was calculated using the Slovin's formula with a $95 \%$ level of confidence to produce the required sample and the purposive sampling method was employed. The number of the population is 68,938 students for both universities and produced a minimum sample of 398 students. The sample size was made up of 267 respondents from the University of Indonesia and 136 respondents from Bogor Agricultural Institute. The purposive sampling method was chosen because the students who participated in this questionnaire were only second-year to final-year students. It was based on the judgment that those students have more learning experiences about sustainability at the university. The number of questionnaires distributed was more than the sample minimum to avoid a low response rate as it is vulnerable to sampling bias. Therefore, the sample of 403 respondents exceeded the minimum sample requirement (398 respondents).

The measurements of all items were done through a 7-point Likert-type scale $(1=$ strongly disagree to $7=$ strongly agree). Personality was adapted from Kvasova (2015) and measured through 17 items. The measurement of attitude toward sustainability was adopted from Kagawa (2007) and included items such as "I think it is a waste of time and effort" and "I think it is a good thing". Sustainable Behaviour (SB) was adapted from Tapia-Fonllem et al. (2013) and was measured through 23 items. The happiness scale was adopted from Lyubomirsky and Lepper (1999) and included items such as "In general, I consider myself happy", "Compared to most of my peers, I consider myself happy", and "I enjoy life, regardless of what's going on". The measurement of life satisfaction was adopted from Diener et al. (1985) and included items such as "In most ways, my life is close to my ideal" and "I am satisfied with my life".

The questionnaires were analysed using Partial Least Squares Path Modeling (PLS-PM) and XLSTAT2020 as the statistical analysis software. PLS-PM is the Partial Least Squares approach to Structural Equation Modeling (SEM). The validity and reliability of the questionnaire were assessed from convergent validity, discriminant validity, and composite reliability. Convergent validity was measured by outer loading value of greater than 0.70 . However, indicators with an outer loading value of between 0.50 and 0.60 were considered sufficient; discriminant validity was measured by Average Variance Extracted (AVE) value of greater than 0.50 ; composite reliability was measured by Cronbach's Alpha value of greater than 0.70 (Hair et al., 2017) and Dillon Goldstein's rho / D.G rho (PCA) value of greater than 0.60 (Bagozzi \& Yi, 1988).

\section{Results and Discussion}

The background characteristics of respondents included gender and age. The students comprised 238 female students (59.1\%) and 165 male students (40.9\%). Of the 403 respondents, 86 students $(21.3 \%)$ and 317 students $(78.7 \%)$ were under the age of 20 years, and between 20 to 25 years, respectively.

The present study proposed a conceptual framework of how personality and attitude affect the practice of sustainable behaviour and the consequence of that practice on happiness and life satisfaction. Figure 1 depicts the conceptual framework, which illustrates the relationships between the variables in the present study.

The measurement model was evaluated for convergent validity and discriminant validity, as well as composite reliability. The composite reliability was assessed by calculating the Cronbach's Alpha and the Dillon Goldstein rho (D.G rho). The first assessment was convergent validity, in which a second reestimation was performed by removing items with outer loading values of below 0.50. Discriminant validity was assessed by Average Variance Extracted (AVE) value of greater than 0.50. The next assessment was composite reliability, in which the acceptable values were at least greater than 0.6. Tables 1 to 3 showed that all constructs in the model complied with the validity and discriminant validity criterion. 


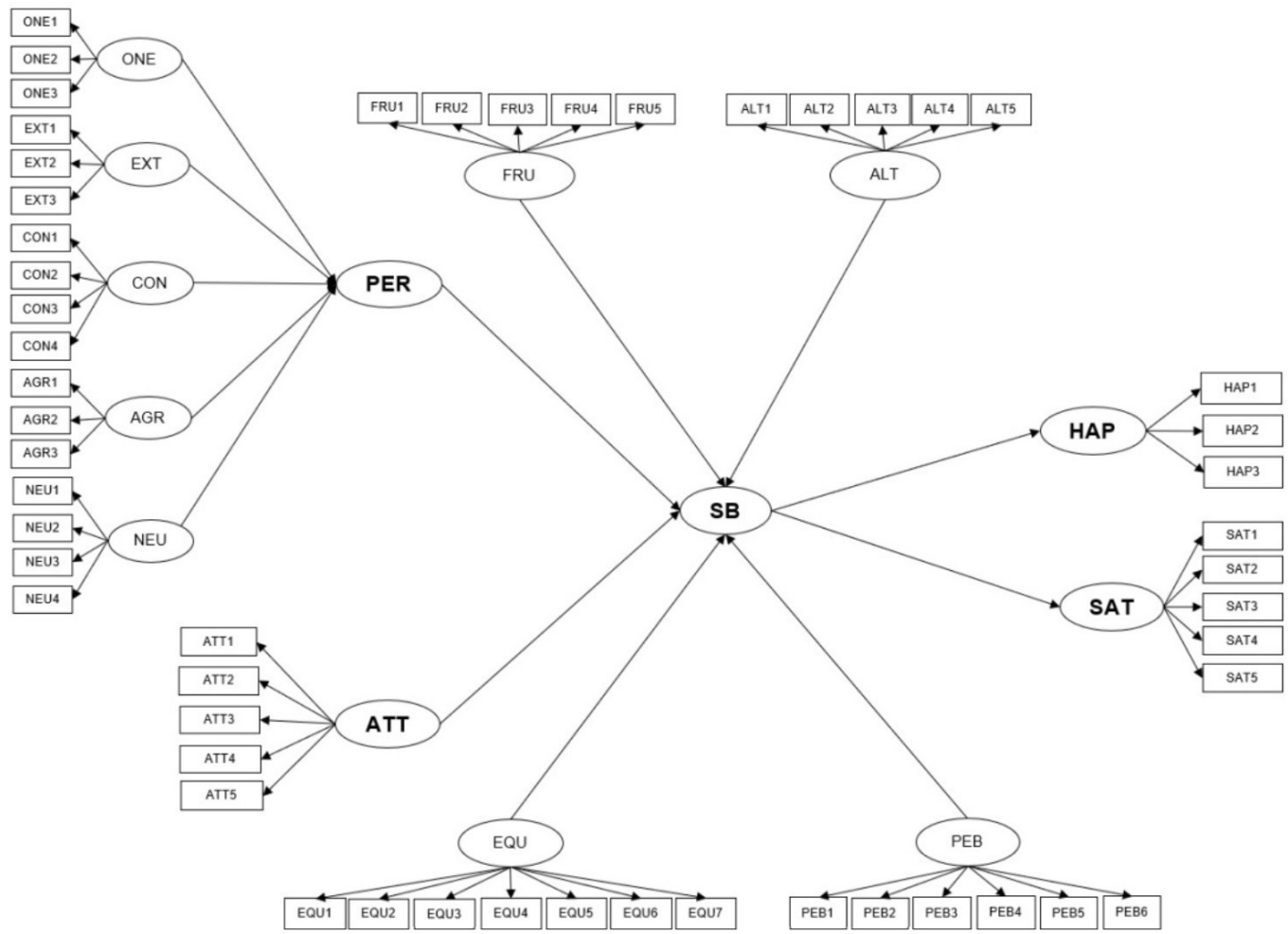

Figure 1: Research framework

Table 1: The assessment of convergent validity

\begin{tabular}{llllllllllll}
\multicolumn{1}{l}{ Factor Loadings } \\
\hline & EXT & CON & AGR & NEU & ATT & FRU & ALT & EQU & PEB & SAT & HAP \\
\hline ONE1 & 0,236 & 0,096 & 0,162 & 0,161 & 0,187 & 0,122 & 0,135 & 0,195 & 0,184 & 0,072 & 0,090 \\
ONE2 & 0,328 & 0,127 & 0,247 & 0,201 & 0,361 & 0,241 & 0,289 & 0,298 & 0,346 & 0,098 & 0,081 \\
ONE3 & 0,253 & 0,131 & 0,186 & 0,257 & 0,265 & 0,181 & 0,119 & 0,169 & 0,167 & 0,086 & 0,020 \\
\hline EXT1 & $\mathbf{0 , 9 2 2}$ & 0,152 & 0,243 & 0,232 & 0,220 & 0,149 & 0,267 & 0,186 & 0,164 & 0,240 & 0,150 \\
EXT2 & $\mathbf{0 , 9 4 4}$ & 0,157 & 0,285 & 0,266 & 0,195 & 0,136 & 0,281 & 0,170 & 0,187 & 0,268 & 0,175 \\
EXT3 & $\mathbf{0 , 8 8 6}$ & 0,128 & 0,217 & 0,228 & 0,157 & 0,086 & 0,100 & 0,107 & 0,107 & 0,258 & 0,146 \\
\hline CON1 & 0,228 & $\mathbf{0 , 7 7 8}$ & 0,272 & 0,228 & 0,136 & 0,194 & 0,210 & 0,124 & 0,167 & 0,378 & 0,198 \\
CON2 & 0,113 & $\mathbf{0 , 7 8 6}$ & 0,163 & 0,263 & 0,142 & 0,197 & 0,180 & 0,200 & 0,228 & 0,310 & 0,160 \\
CON3 & 0,124 & $\mathbf{0 , 8 1 9}$ & 0,299 & 0,151 & 0,149 & 0,150 & 0,288 & 0,247 & 0,218 & 0,315 & 0,101 \\
CON4 & $-0,013$ & $\mathbf{0 , 6 6 8}$ & 0,269 & 0,190 & 0,227 & 0,280 & 0,294 & 0,243 & 0,251 & 0,162 & 0,032 \\
\hline AGR1 & 0,195 & 0,345 & $\mathbf{0 , 8 0 4}$ & 0,123 & 0,387 & 0,288 & 0,418 & 0,447 & 0,417 & 0,209 & 0,173 \\
AGR2 & 0,281 & 0,297 & $\mathbf{0 , 8 8 2}$ & 0,272 & 0,268 & 0,257 & 0,392 & 0,298 & 0,318 & 0,315 & 0,203 \\
AGR3 & 0,204 & 0,179 & $\mathbf{0 , 8 4 4}$ & 0,185 & 0,222 & 0,203 & 0,317 & 0,265 & 0,278 & 0,141 & 0,121 \\
\hline NEU1 & 0,215 & 0,235 & 0,221 & $\mathbf{0 , 7 9 7}$ & 0,133 & 0,216 & 0,251 & 0,066 & 0,261 & 0,259 & 0,258 \\
NEU2 & 0,106 & 0,086 & 0,135 & $\mathbf{0 , 6 6 5}$ & 0,194 & 0,097 & 0,157 & 0,116 & 0,091 & 0,184 & 0,309 \\
NEU3 & 0,209 & 0,262 & 0,211 & $\mathbf{0 , 8 5 2}$ & 0,189 & 0,278 & 0,249 & 0,062 & 0,265 & 0,420 & 0,373 \\
NEU4 & 0,287 & 0,255 & 0,172 & $\mathbf{0 , 8 7 1}$ & 0,183 & 0,182 & 0,178 & 0,038 & 0,188 & 0,435 & 0,430 \\
\hline ATT1 & 0,139 & 0,198 & 0,330 & 0,198 & $\mathbf{0 , 8 3 1}$ & 0,362 & 0,354 & 0,252 & 0,335 & 0,138 & 0,115 \\
ATT2 & 0,130 & 0,234 & 0,279 & 0,200 & $\mathbf{0 , 8 6 1}$ & 0,343 & 0,347 & 0,264 & 0,355 & 0,155 & 0,079 \\
ATT3 & 0,172 & 0,176 & 0,274 & 0,161 & $\mathbf{0 , 8 5 6}$ & 0,283 & 0,337 & 0,260 & 0,327 & 0,139 & 0,060 \\
ATT4 & 0,222 & 0,163 & 0,289 & 0,115 & $\mathbf{0 , 8 6 8}$ & 0,276 & 0,281 & 0,274 & 0,313 & 0,153 & 0,095 \\
ATT5 & 0,210 & 0,117 & 0,283 & 0,213 & $\mathbf{0 , 8 0 3}$ & 0,296 & 0,326 & 0,320 & 0,404 & 0,192 & 0,164 \\
\hline
\end{tabular}

Journal of Sustainability Science and Management Volume 16 Number 7, October 2021: 80-92 


\begin{tabular}{|c|c|c|c|c|c|c|c|c|c|c|c|}
\hline FRU1 & 0,056 & 0,157 & 0,158 & 0,185 & 0,282 & 0,588 & 0,146 & 0,170 & 0,257 & 0,064 & 0,118 \\
\hline FRU4 & 0,075 & 0,181 & 0,233 & 0,107 & 0,330 & 0,763 & 0,414 & 0,131 & 0,452 & 0,079 & 0,076 \\
\hline FRU5 & 0,155 & 0,229 & 0,236 & 0,263 & 0,197 & 0,786 & 0,352 & 0,155 & 0,347 & 0,176 & 0,217 \\
\hline ALT1 & 0,168 & 0,265 & 0,336 & 0,112 & 0,334 & 0,416 & 0,785 & 0,279 & 0,435 & 0,180 & 0,223 \\
\hline ALT2 & 0,216 & 0,286 & 0,394 & 0,238 & 0,295 & 0,385 & 0,865 & 0,229 & 0,546 & 0,230 & 0,224 \\
\hline ALT3 & 0,220 & 0,271 & 0,399 & 0,282 & 0,292 & 0,395 & 0,835 & 0,241 & 0,492 & 0,211 & 0,224 \\
\hline ALT4 & 0,201 & 0,205 & 0,343 & 0,236 & 0,284 & 0,343 & 0,825 & 0,175 & 0,480 & 0,261 & 0,205 \\
\hline ALT5 & 0,175 & 0,252 & 0,355 & 0,206 & 0,408 & 0,296 & 0,786 & 0,339 & 0,381 & 0,156 & 0,182 \\
\hline EQU1 & 0,112 & 0,116 & 0,199 & 0,099 & 0,207 & 0,071 & 0,146 & 0,538 & 0,183 & 0,103 & 0,022 \\
\hline EQU4 & 0,139 & 0,215 & 0,289 & 0,075 & 0,238 & 0,195 & 0,283 & 0,809 & 0,321 & 0,139 & 0,081 \\
\hline EQU5 & 0,141 & 0,184 & 0,275 & 0,102 & 0,168 & 0,114 & 0,171 & 0,512 & 0,104 & 0,210 & 0,061 \\
\hline EQU6 & 0,097 & 0,161 & 0,317 & $-0,014$ & 0,288 & 0,150 & 0,237 & 0,781 & 0,272 & 0,051 & 0,011 \\
\hline EQU7 & 0,117 & 0,220 & 0,302 & 0,057 & 0,231 & 0,151 & 0,200 & 0,770 & 0,288 & 0,109 & 0,047 \\
\hline PEB1 & 0,122 & 0,214 & 0,348 & 0,219 & 0,342 & 0,450 & 0,504 & 0,288 & 0,836 & 0,296 & 0,225 \\
\hline PEB2 & 0,207 & 0,266 & 0,396 & 0,278 & 0,352 & 0,376 & 0,538 & 0,305 & 0,857 & 0,336 & 0,246 \\
\hline PEB3 & 0,102 & 0,163 & 0,251 & 0,185 & 0,319 & 0,319 & 0,444 & 0,229 & 0,772 & 0,238 & 0,135 \\
\hline PEB4 & 0,080 & 0,204 & 0,241 & 0,060 & 0,347 & 0,291 & 0,266 & 0,404 & 0,564 & 0,091 & 0,059 \\
\hline PEB5 & 0,092 & 0,223 & 0,292 & 0,139 & 0,276 & 0,442 & 0,362 & 0,253 & 0,743 & 0,170 & 0,101 \\
\hline PEB6 & 0,150 & 0,210 & 0,293 & 0,278 & 0,292 & 0,434 & 0,475 & 0,185 & 0,801 & 0,353 & 0,254 \\
\hline SAT1 & 0,304 & 0,357 & 0,214 & 0,319 & 0,192 & 0,123 & 0,204 & 0,105 & 0,267 & 0,822 & 0,454 \\
\hline SAT2 & 0,229 & 0,305 & 0,229 & 0,330 & 0,188 & 0,146 & 0,186 & 0,111 & 0,295 & 0,850 & 0,489 \\
\hline SAT3 & 0,214 & 0,319 & 0,236 & 0,383 & 0,136 & 0,143 & 0,226 & 0,164 & 0,239 & 0,840 & 0,602 \\
\hline SAT4 & 0,211 & 0,291 & 0,217 & 0,342 & 0,142 & 0,085 & 0,256 & 0,180 & 0,332 & 0,802 & 0,508 \\
\hline SAT5 & 0,094 & 0,295 & 0,158 & 0,287 & 0,029 & 0,105 & 0,080 & 0,055 & 0,119 & 0,617 & 0,403 \\
\hline HAP1 & 0,170 & 0,163 & 0,191 & 0,423 & 0,156 & 0,172 & 0,238 & 0,040 & 0,236 & 0,611 & 0,928 \\
\hline HAP2 & 0,176 & 0,184 & 0,120 & 0,390 & 0,034 & 0,112 & 0,166 & 0,037 & 0,160 & 0,575 & 0,878 \\
\hline HAP3 & 0,123 & 0,116 & 0,208 & 0,343 & 0,126 & 0,203 & 0,273 & 0,090 & 0,212 & 0,496 & 0,884 \\
\hline
\end{tabular}

Note. $\mathrm{ONE}=$ openness to new experience; EXT $=$ extraversion; $\mathrm{CON}=$ conscientiousness; $\mathrm{AGR}=$ agreeableness; $\mathrm{NEU}=$ neuroticism; $\mathrm{ATT}=$ attitude; FRU = frugal; $\mathrm{ALT}=$ altruistic; $\mathrm{EQU}=$ equitable; $\mathrm{PEB}=$ pro-ecological behaviour; HAP = happiness; $\mathrm{SAT}=$ satisfaction with life

Table 2: The assessment of discriminant validity

\begin{tabular}{|c|c|c|c|c|c|c|c|c|c|c|c|c|c|c|}
\hline \multicolumn{15}{|l|}{ AVE } \\
\hline & ONE & EXT & $\mathrm{CON}$ & AGR & NEU & $A \Pi$ & PB & FRU & ALT & EQU & PEB & SAT & HAP & (AVE) \\
\hline ONE & 1 & 0,111 & 0,021 & 0,059 & 0,064 & 0,113 & 0,109 & 0,050 & 0,051 & 0,073 & 0,083 & 0,011 & 0,006 & 0,679 \\
\hline EXT & 0,111 & 1 & 0,025 & 0,074 & 0,070 & 0,043 & 0,059 & 0,018 & 0,058 & 0,029 & 0,028 & 0,077 & 0,029 & 0,842 \\
\hline CON & 0,021 & 0,025 & 1 & 0,107 & 0,075 & 0,043 & 0,135 & 0,069 & 0,098 & 0,067 & 0,077 & 0,153 & 0,028 & 0,585 \\
\hline AGR & 0,059 & 0,074 & 0,107 & 1 & 0,054 & 0,119 & 0,268 & 0,088 & 0,200 & 0,158 & 0,160 & 0,073 & 0,040 & 0,712 \\
\hline NEU & 0,064 & 0,070 & 0,075 & 0,054 & 1 & 0,046 & 0,088 & 0,062 & 0,069 & 0,007 & 0,068 & 0,175 & 0,183 & 0,641 \\
\hline$A \Pi T$ & 0,113 & 0,043 & 0,043 & 0,119 & 0,046 & 1 & 0,248 & 0,138 & 0,153 & 0,108 & 0,173 & 0,035 & 0,016 & 0,713 \\
\hline FRU & 0,050 & 0,018 & 0,069 & 0,088 & 0,062 & 0,138 & 0,409 & 1 & 0,201 & 0,042 & 0,254 & 0,023 & 0,035 & 0,515 \\
\hline ALT & 0,051 & 0,058 & 0,098 & 0,200 & 0,069 & 0,153 & 0,704 & 0,201 & 1 & 0,094 & 0,327 & 0,064 & 0,067 & 0,672 \\
\hline EQU & 0,073 & 0,029 & 0,067 & 0,158 & 0,007 & 0,108 & 0,310 & 0,042 & 0,094 & 1 & 0,125 & 0,027 & 0,004 & 0,582 \\
\hline PEB & 0,083 & 0,028 & 0,077 & 0,160 & 0,068 & 0,173 & 0,765 & 0,254 & 0,327 & 0,125 & 1 & 0,111 & 0,053 & 0,590 \\
\hline SAT & 0,011 & 0,077 & 0,153 & 0,073 & 0,175 & 0,035 & 0,108 & 0,023 & 0,064 & 0,027 & 0,111 & 1 & 0,386 & 0,625 \\
\hline HAP & 0,006 & 0,029 & 0,028 & 0,040 & 0,183 & 0,016 & 0,071 & 0,035 & 0,067 & 0,004 & 0,053 & 0,386 & 1 & 0,805 \\
\hline (AVE) & 0,679 & 0,842 & 0,585 & 0,712 & 0,641 & 0,713 & 0,339 & 0,515 & 0,672 & 0,582 & 0,590 & 0,625 & 0,805 & 0 \\
\hline
\end{tabular}


Table 3: The assessment of composite reliability

\begin{tabular}{lcc}
\hline & Cronbach Alpha & D.G. rho (PCA) \\
\hline ONE & 0.765 & 0.864 \\
EXT & 0.906 & 0.941 \\
CON & 0.762 & 0.849 \\
AGR & 0.798 & 0.882 \\
NEU & 0.811 & 0.877 \\
ATT & 0.899 & 0.926 \\
FRU & 0.536 & 0.764 \\
ALT & 0.878 & 0.911 \\
EQU & 0.722 & 0.819 \\
PEB & 0.857 & 0.895 \\
SAT & 0.850 & 0.894 \\
HAP & 0.880 & 0.926 \\
\hline
\end{tabular}

Figure 2 depicts a model of interrelations between personality, attitude, sustainable behaviour, happiness and life satisfaction. The measurement model of the structural equation analysis produced significant factor loadings between every factor and their corresponding indicators $(\mathrm{p}<0.05)$. The personality (structural coefficient $=0.556 ; \mathrm{p}<0.05)$ and attitude (structural coefficient $=0.497 ; \mathrm{p}<0.05$ ) influenced sustainable behaviour. In turn, happiness (structural coefficient $=0.267 ; \mathrm{p}$ $<0.05$ ) and life satisfaction (structural coefficient $=0.330 ; \mathrm{p}<0.05$ ) were affected by sustainable behaviour. Goodness of Fit (GoF) and relative

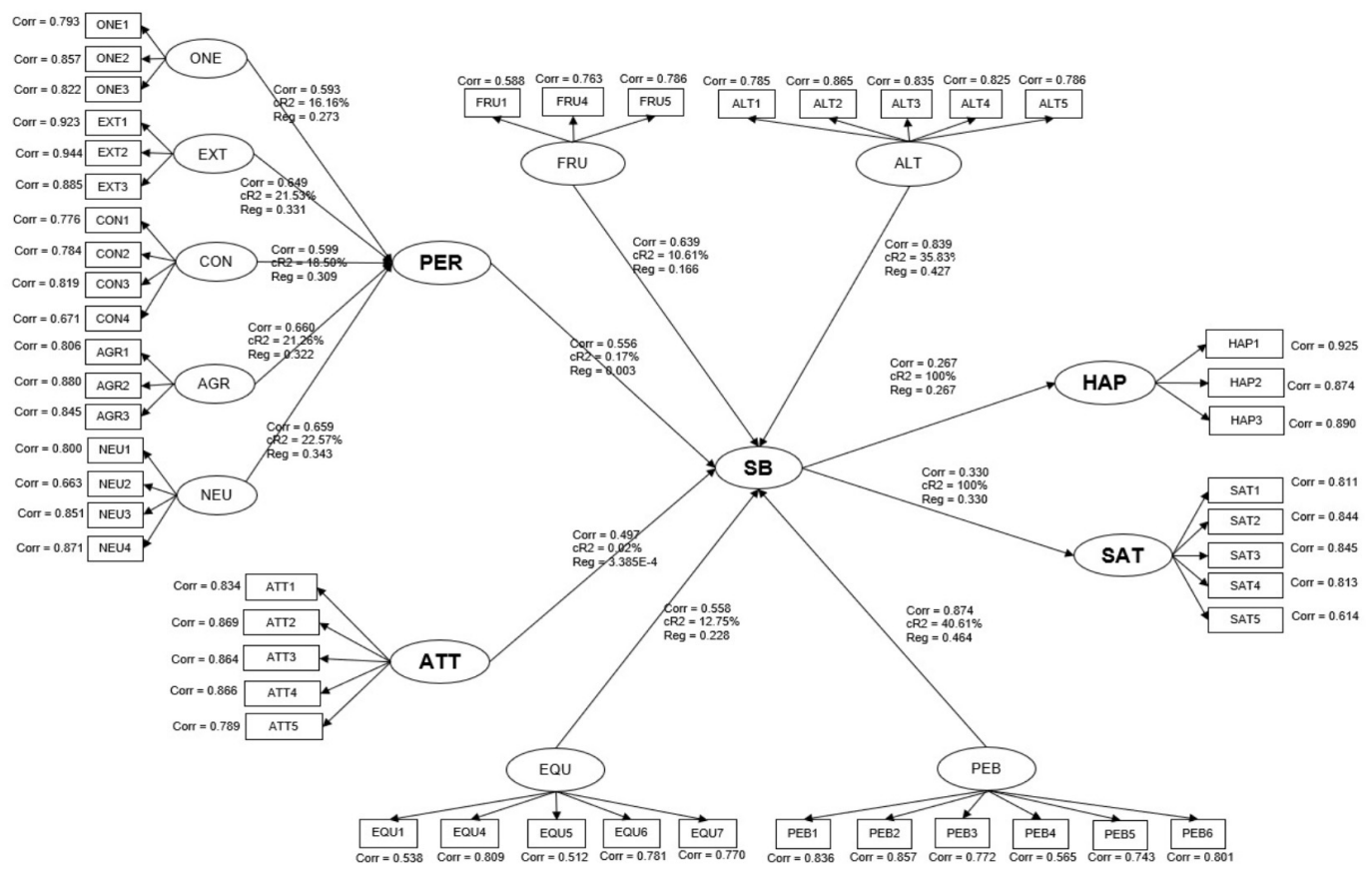

Figure 2: Results of the path analysis

Note. $\mathrm{PER}=$ personality; $\mathrm{ONE}=$ openness to new experience; $\mathrm{EXT}=$ extraversion; $\mathrm{CON}=$ conscientiousness; $\mathrm{AGR}=$ agreeableness; $\mathrm{NEU}=$ neuroticism $; \mathrm{ATT}=$ attitude $\mathrm{SB}=$ sustainable behaviour; FRU $=$ frugal; $\mathrm{ALT}=$ altruistic; $\mathrm{EQU}=$ equitable; $\mathrm{PEB}=$ pro-ecological behaviour; $\mathrm{HAP}=$ happiness; $\mathrm{SAT}=$ satisfaction with life 
$\mathrm{GoF}\left(\mathrm{GoF}_{\text {rel }}\right)$ of the model were 0.561 and 0.884 , respectively. The relative $\mathrm{GoF}_{\text {rel }}$ is high and reflects a good fit of the model to the data.

The relationship among variables contained in t-statistic is significant in 5\% tests (see Table 4). The hypothesis testing results where personality exert a significant influence on sustainable behaviour, attitude has no statistical significance on sustainable behaviour, and sustainable behaviour has significant influence on both happiness and life satisfaction.

Path coefficient for personality is seen in Table 5. Neuroticism (NEU) has a greater weighting (0.343), followed by extraversion (0.331), agreeableness (0.322), conscientiousness (0.309), and openness to experience $(0.273)$.

Among theories of personality, the trait approach to personality focuses on individual differences. Specifically within the field of the environment, personality can influence the likelihood of engagement in environmental practices (Costa \& Mccrae, 2012). Furthermore, people with different personality traits respond differently towards some environmentally friendly actions (Fraj \& Martinez, 2006. This study demonstrated that students' personality influenced sustainable behaviour. The stronger the personality related to the environment, the more the students are involved in sustainability behaviour practices. A good personality will cause students to be responsible for conserving natural resources and practising sustainable behaviour. All personality traits achieved statistical significance. Neuroticism had the highest associations among the personality traits and openness had the lowest associations (Table 5). Neuroticism is the trait disposition to experience negative effects, including emotional instability. Rationally, emotional instability can prevent an individual from behaving sustainably. Even so, it is not always the case for neuroticism. The emotional reaction of neurotic people is stronger when they experience environmental degradation directly (Newhouse, 1990). Hence, it can encourage or motivate students because practising sustainable behaviour will help them reduce or avert negative emotions. In addition, neurotic students who have been stressed with the environmental degradation could result in sustainable behaviour, even for specific behaviour such as purchasing and using eco-friendly products. Previous research has demonstrated the relationship between neuroticism and environmental behaviour (Milfont \& Sibley, 2012; Kvasova, 2015).

Table 4: Path coefficient, standard error, and t-statistic

\begin{tabular}{cccccc}
\hline Hypothesis & Relationship & Path Coefficient & Standard Error & T-statistic & P Value \\
\hline 1 & PER -> SB & 0.003 & 0.001 & 4.050 & 0.000 \\
2 & ATT -> SB & 0.000 & 0.001 & 0.451 & 0.652 \\
3 & SB -> HAPP & 0.267 & 0.048 & 5.552 & 0.000 \\
4 & SB -> SAT & 0.330 & 0.047 & 7.004 & 0.000 \\
\hline
\end{tabular}

Table 5: Path cefficient for personality

Path coefficients (PERSONALITY / 1):

\begin{tabular}{cccccc}
\hline Latent Variable & Value & Standard Error & $\mathbf{t}$ & $\mathbf{P r}>|\mathbf{t}|$ & Critical Ratio (CR) \\
\hline ONE & 0,273 & 0,001 & 458,718 & 0,000 & 13,733 \\
EXT & 0,331 & 0,001 & 552,436 & 0,000 & 17,849 \\
CON & 0,309 & 0,001 & 521,794 & 0,000 & 16,335 \\
AGR & 0,322 & 0,001 & 534,693 & 0,000 & 17,209 \\
NEU & 0,343 & 0,001 & 577,505 & 0,000 & 15,821 \\
\hline
\end{tabular}


A positive attitude towards nature involves attempts to improve the environment while a negative attitude involves no effort to protect and conserve the environment and even perform an action to harm the environment. The present study demonstrated no significant relationship between attitude and sustainable behaviour. Students' attitude is not enough to drive them to behave sustainably. In practice, a positive attitude towards environment generally will involve sustainable behaviours. Students may express positive attitudes about the environment, but it may not be always reflected in their actions. The present findings were consistent with $\mathrm{Fu}$ et al. (2018), but contradicted with Altinigne and Bilgin (2015). Inconsistency may emerge when students who consider themselves as someone who care for the environment but do not behave accordingly. The inconsistency between student attitudes and their actual sustainable behaviour is known as the attitude-behaviour gap. This gap indicates the failure of an individual to translate environmental attitude into proenvironmental behaviour. Bamberg and Möser (2007) demonstrated the attitude-behaviour gap towards pro-environmental behaviour.

The concept of human well-being is to link human life and the natural environment. Several studies have linked human activities and environmental degradation that threatens human well-being. Happiness and life satisfaction are separate constructs. Happiness relates more to affect or feelings and life satisfaction relates more to the cognitive assessment of life as a whole (Erdogan et al., 2012). Studies have demonstrated that happiness and satisfaction with life are psychological consequences of sustainability. While most of happiness is related to material consumption, the non-material is related to enjoying the nature. Students who spend more recreational time in nature, attributed a mind to nature, high connectedness to nature and have a greater appreciation of the natural environment exhibit more sustainable behaviours. By behaving in sustainable ways, students can minimise the damage to the environment and the practice produces happiness. This findings were consistent with other studies that sustainable behaviour influences happiness (Corral-Verdugo et al., 2011; Tapia-Fonllem et al., 2013; Choi, 2016).

Poor environmental quality may contribute to a decrease in life satisfaction. The links between environmental conditions and life satisfaction have often been studied (Rajani et al., 2019). This study found that sustainable behaviours (pro-ecological, altruistic, frugal and equitable) influence life satisfaction. In regards to frugal action, De Young (1986) found that recycling and reusing materials relate to satisfaction from frugality. Welsch and Kühling (2010) found a significant positive relationship between recycling and life satisfaction. CorralVerdugo et al. (2016) found that sustainable behaviour exhibited by frugal and equitable actions is significantly related to positive intrinsic consequences, namely satisfaction. The present findings added evidence to the literature suggesting that sustainable behaviour contributes to life satisfaction (Welsch \& Kühling, 2010; Schmitt et al., 2018). The sustainable practices contribute positively to natural life and the life of students themselves, even for simple eco-friendly practices, such as turning off the air conditioner when leaving the room or sorting plastic waste.

In general, students who behave sustainably will support initiatives and ideas of sustainability by involving themselves personally and committing to sustainability practices. Engagement and commitment form the basis for change at a broader level, namely society. When sustainable behaviour is accepted in an individual, family, and community, the practice of sustainable behaviour will be more easily formed. Familiarising the self with the consequences of behaviour towards nature, other people, now and in the future, and repeating behavioural actions into habits, sustainable behaviour can become a moral standard.

\section{Conclusion}

The present study analysed how sustainable behaviour of university students is structured. Students' active participation and involvement in 
sustainability practice can influence the success of sustainable behaviour. Although individual differences (attitudes and personality) can drive people to engage in sustainable behaviours and improve human well-being (happiness and satisfaction to life) from that action, there are still other barriers to environmental action. Nevertheless, examining antecedents and consequences may give insights into how they shape sustainable behaviour. In contrast to personality that has a significant influence on sustainable behaviour, attitude has no significant influence on sustainable behaviour. When students feel that attitude towards sustainability do not have a high importance in their life, then this attitude is not important to them and does not have a strong influence on the behaviour. Therefore, attitudes can have a strong impact on behaviour only when students feel the importance of having a sustainability attitude.

The present study also focused on the associations of the two key subjective dimensions of well-being, life satisfaction and happiness among students. The more often students engage in sustainable behaviour, the happier they become, and induce a higher life satisfaction. Future research is required to (1) investigate further non-significant hypothesis; and (2) investigate the intricate relationship between neuroticism and sustainable behaviour because neurotic people tend to experience negative emotions that can hinder behaviour, and (3) extend the sample size to other campus stakeholders (faculty members and administrators/staff) to determine if there is differentiation of results from the sample students.

This research contributed to sustainable behaviour studies in understanding why students are involved sustainable behaviour. Universities should promote, educate, adopt, and practice the concept of sustainability (sustainable behaviour) through the design of sustainability based on teaching and curriculum, campus operations, as well as assist the government in the role of facilitator and mediator in the transition of sustainable community life. Furthermore, the university must prevent the emergence of antienvironmental behaviour by implementing environmentally oriented policies/sanctions.

\section{Acknowledgements}

The authors extend their gratitude to reviewers for critical comments on the manuscript and the university for the research opportunity.

\section{References}

Abubakar, I. R., Al-Shihri, F. S., \& Ahmed, S. M. (2016). Students' assessment of campus sustainability at the University of Dammam, Saudi Arabia. Sustainability (Switzerland), 8(1), 1-14.

Ahmad, J., Md. Noor, S., \& Ismail, N. (2015). Investigating students' environmental knowledge, attitude, practice and communication. Asian Social Science, 11(16), 284-293.

Alshuwaikhat, H. M., Adenle, Y. A., \& Saghir, B. (2016). Sustainability assessment of higher education institutions in Saudi Arabia. Sustainability (Switzerland), 8(8).

Altinigne, N., \& Bilgin, Z. (2015). The effect of environmental attitudes on environmentally conscious behavior of university students. 145th International Marketing Trends Conference, Paris, January, 1-12.

Amaral, L. P., Martins, N., \& Gouveia, J. B. (2015). Quest for a sustainable university: A review. International Journal of Sustainability in Higher Education, 16(2), 155-172.

Arnocky, S., Milfont, T. L., \& Nicol, J. R. (2014). Time perspective and sustainable behavior: Evidence for the distinction between consideration of immediate and future consequences. Environment and Behavior, 46(5).

Bagozzi, R. P., \& Yi, Y. (1988). On the evaluation of structural equation models. Journal of the Academy of Marketing Science,16(1), 74-94. 
Bamberg, S., \& Möser, G. (2007). Twenty years after Hines, Hungerford, and Tomera: A new meta-analysis of psycho-social determinants of pro-environmental behaviour. Journal of Environmental Psychology, 27(1), 14-25.

Bechtel, R. B., \& Corral-Verdugo, V. (2010). Happiness and sustainable behavior. In V. Corral-Verdugo, C. Garci'a, \& M. Fri'as (Eds.), Psychological approaches to sustainability: Current trends in theory, research and applications. New York, NY: Nova Science Publishers.

Bonnes, M., \& Bonaiuto, M. (2002). Environmental psychology: From spatialphysical environment to sustainable development. Handbook of Environmental Psychology, January, 28-54.

Brown, K. W., \& Kasser, T. (2005). Are psychological and ecological well-being compatible? The role of values, mindfulness, and lifestyle. Social Indicators Research, 74(2), 349-368.

Choi, J. (2016). Sustainable behavior: Study engagement and happiness among university students in South Korea. Sustainability (Switzerland), 8(7), 1-11.

Corral-Verdugo, V, Mireles-Acosta, J., TapiaFonllem, C., \& Fraijo-Sing, B. (2011). Happiness as correlate of sustainable behavior: A study of pro-ecological, frugal, equitable and altruistic actions that promote subjective wellbeing. Human Ecology Review, 18(2), 95-104.

Corral-Verdugo, Víctor, González-Lomelí, D., Rascón-Cruz, M., \& Corral-Frías, V. O. (2016). Intrinsic motives of autonomy, self-efficacy, and satisfaction associated with two instances of sustainable behavior: Frugality and equity. Psychology, 07(05), 662-671.

Corral-Verdugo, Victor, Tapia-Fonllem, C., \& Ortiz-Valdez, A. (2015). On the relationship between character strengths and sustainable behavior. Environment and Behavior, 47(8), 877-901.
Costa, P. T., \& Mccrae, R. R. (2012). The Five-Factor Model, Five-Factor Theory, and Interpersonal Psychology. Handbook of Interpersonal Psychology: Theory, Research, Assessment, and Therapeutic Interventions, 91-104.

De Young, R. (1986). Some psychological aspects of recycling the structure of conservation-satisfactions. Environment and Behavior, 18(65), 435-449.

Di Tella, R., \& MacCulloch, R. (2008). Gross national happiness as an answer to the Easterlin Paradox? Journal of Development Economics, 86(1), 22-42.

Diener, E., Emmons, R. A., Larsen, R. J., \& Griffin, S. (1985). The satisfaction with life scale. Journal of Personality Assessment ISSN: 71-75.

Erdogan, B., Bauer, T. N., Truxillo, D. M., \& Mansfield, L. R. (2012). Whistle while you work: A review of the life satisfaction literature. Journal of Management, 38(4), 1038-1083.

Ferreira, S., Akay, A., Brereton, F., Cuñado, J., Martinsson, P., Moro, M., \& Ningal, T. F. (2013). Life satisfaction and air quality in Europe. Ecological Economics, 88, 1-10.

Ferrer-i-Carbonell, A., \& Gowdy, J. (2007). Environmental degradation and happiness. Ecological Economics, 60, 509-516. 10.1016/j.Ecolecon.2005.12.005., 0, 509516.

Fraj, E., \& Martinez, E. (2006). Influence of personality on ecological consumer behaviour. Journal of Consumer Behaviour, 167-181.

Fu, L., Zhang, Y., Xiong, X., \& Bai, Y. (2018). Pro-environmental awareness and behaviors on campus: Evidence from Tianjin, China. Eurasia Journal of Mathematics, Science and Technology Education, 14(1), 427-445.

Gardner, G., \& Prugh, T. (2008). Seeding the sustainable economy. In State of the World (pp. 3-17). 
Griffin, R. . (2013). Management. South Western Cengage Learning.

Hair, J. F., Hult, G. T. M., Ringle, C. M., \& Sarstedt, M. (2017). A primer on Partial Least Squares Structural Equation Modeling (PLS-SEM). In Sage. Thousand Oaks, CA: Sage.

Huber, L. R., Sloof, R., \& Van Praag, M. (2017). The effect of incentives on sustainable behavior: evidence from a field experiment. Labour Economics, 45, 92-106.

John, O. P., \& Srivastava, S. (1999). The Big-Five Trait Taxonomy: History, measurement, and theoretical perspectives. In Pervin, L. A., \& John, O. P. (Eds.), Handbook of personality: Theory and research, Vol. 2, (pp. 102-138.). New York: Guilford Press.

Juárez-nájera， M. (2010). Personality factors at the base of sustainable behavior. A first approach across two universities. Environmental Management, 1-9.

Juárez-Nájera, M., Rivera-Martínez, J. G., \& Hafkamp, W. A. (2010). An explorative socio-psychological model for determining sustainable behavior: Pilot study in German and Mexican Universities. Journal of Cleaner Production, 18(7), 686-694.

Kagawa, F. (2007). Dissonance in students' perceptions of sustainable development and sustainability: Implications for curriculum change. International Journal of Sustainability in Higher Education, 8(3), 317-338.

Kaiser, F. G., Wölfing, S., \& Fuhrer, U. (1999). Environmental attitude and ecological behaviour. Journal of Environmental Psychology, 19(1), 1-19.

Kotchen, M. J., \& Reiling, S. D. (2000). Environmental attitudes, motivations, and contingent valuation of nonuse values: A case study involving endangered species. Ecological Economics, 32(1), 93-107.

Kvasova, O. (2015). The Big Five personality traits as antecedents of eco-friendly tourist behavior. Personality and Individual Differences, 83, 111-116.

Lyubomirsky, S., \& Lepper, H. S. (1999). Subjective Happiness Scale ( also known as General Happiness Scale ). Social Indicators Research, 46, 137-155.

Mainieri, T., Barnett, E. G., Valdero, T. R., Unipan, J. B., \& Oskamp, S. (1997). Green buying: The influence of environmental concern on consumer behavior. Journal of Social Psychology, 137(2), 189-204.

Milfont, T. L., \& Sibley, C. G. (2012). The Big Five personality traits and environmental engagement: Associations at the individual and societal level. Journal of Environmental Psychology, 32(2), 187-195.

Mostafa, M. M. (2007). Gender differences in Egyptian consumers' green purchase behaviour: The effects of environmental knowledge, concern and attitude. International Journal of Consumer Studies, 31(3), 220-229.

Mullins, J. (2016). Management \& Organizational Behavior. Pearson Education.

Newhouse, N. (1990). Implications of attitude and behavior research for environmental conservation. Journal of Environmental Education, 22(1), 26-32.

Orru, K., Orru, H., Maasikmets, M., Hendrikson, R., \& Ainsaar, M. (2016). Well-being and environmental quality: Does pollution affect life satisfaction? Quality of Life Research, 25(3), 699-705.

Polonsky, M. J., Vocino, A., Grau, S. L., Garma, R., \& Ferdous, A. S. (2012). The impact of general and carbon-related environmental knowledge on attitudes and behaviour of US consumers. Journal of Marketing Management, 28(3-4), 238-263.

Poškus, M. S. (2018). Personality and proenvironmental behaviour. Journal of Epidemiology and Community Health, 72(11), 969-970. 
Rajani, N. B., Skianis, V., \& Filippidis, F. T. (2019). Association of environmental and sociodemographic factors with life satisfaction in 27 European countries. BMC Public Health, 19(1), 1-8.

Schmitt, M. T., Aknin, L. B., Axsen, J., \& Shwom, R. L. (2018). Unpacking the relationships between pro-environmental behavior, life satisfaction, and perceived ecological threat. Ecological Economics, 143, 130-140.

Tapia-Fonllem, C., Corral-Verdugo, V., FraijoSing, B., \& Durón-Ramos, M. F. (2013). Assessing sustainable behavior and its correlates: A measure of pro-ecological, frugal, altruistic and equitable actions. Sustainability (Switzerland), 5(2), 711-723.

Tiwari, A. ., \& Mutascu, M. (2015). The relationship between environmental degradation and happiness in 23 developed contemporary economies. Management of Environmental Quality: An International Journal, 26(2), 301-321.

UNESCO. (2009). United Nations Decade of Education for Sustainable Development (DESD, 2005-2014), Review of Context and Structures for Education for Sustainable Development 2009. Environment: Science and Policy for Sustainable Development, 51, 8-10.

Van Horen, F., Van der Wal, A., \& Grinstein, A. (2018). Green, greener, greenest: Can competition increase sustainable behavior? Journal of Environmental Psychology, 59, 16-25.

Vlek, C., \& Steg, L. (2007). Human behavior and environmental sustainability: Problems, driving forces, and research topics. Journal of Social Issues, 63(August 2015), 1-19.

Wang, E., \& Kang, N. (2019). Does life satisfaction matter for pro-environmental behavior? Empirical evidence from China General Social Survey. Quality and Quantity, 53(1), 449-469.

Welsch, H., \& Kühling, J. (2009). Determinants of pro-environmental consumption: The role of reference groups and routine behavior. Ecological Economics, 69(1), 166-176.

Welsch, H., \& Kühling, J. (2010). Proenvironmental behavior and rational consumer choice: Evidence from surveys of life satisfaction. Journal of Economic Psychology, 31(3), 405-420. 